UDC 343.242 .4

LBC 67.408.031

\title{
DIFFERENTIATING ELEMENTS OF EXEMPTION FROM CRIMINAL LIABILITY IN CONNECTION WITH SETTLEMENT WITH THE INJURED PARTY UNDER THE CRIMINAL CODES OF THE RUSSIAN FEDERATION, THE REPUBLIC OF BELARUS AND THE REPUBLIC OF KAZAKHSTAN
}

\author{
Larisa N. Larionova \\ Volgograd State University, Volgograd, Russian Federation \\ Igor O. Gruntov \\ Belarusian State University, Minsk, Republic of Belarus \\ Dmitry G. Moroz \\ Belarusian State University, Minsk, Republic of Belarus
}

\begin{abstract}
Introduction: the article deals with the comparative law analysis of the norms of the Russian Criminal Code, the Criminal Code of the Republic of Belarus and the Criminal Code of the Republic of Kazakhstan governing the exemption from criminal responsibility in connection with the settlement with the injured party, as well as the official viewpoints on the same issues reflected in the relevant decisions of the Supreme Judicial Authorities of these states. The goals and objectives are to identify the differences in the regulation of this type of exemption under the criminal laws of the Russian Federation, Belarus and Kazakhstan, to search for the best variants of their description in the law and acts of official interpretation. Methods: the main method of scientific cognition was a comparative law study; moreover, there were involved the formal logical and structural system techniques. Results: there was analyzed a system of conditions with which the legislators of Russia, Belarus and Kazakhstan associate the possibility of exemption from criminal responsibility because of the settlement with the injured party; and on the basis of the features of their description in the legislation, as well as the characteristics in the decisions of the Supreme Judicial Authorities there were identified generic, similar aspects and the "national" characteristics inherent in the relevant legal phenomenon. The attempt to determine the differentiating effect of the individual conditions for the exemption from criminal liability was made. Some of the drawbacks of the analyzed regulations were highlighted. Scope of application: it is intended for use in the legislative and law-enforcement activities, as well as in the scientific work. There were drawn the conclusions on the presence of the possibilities to enhance the differentiating $\approx$ potential of the conditions of exemption from criminal responsibility in connection with the settlement with the injured party in the Criminal Codes of the Russian Federation and the Republic of Belarus; it was proposed to make changes and additions to these laws and Resolution No. 19 of the Plenum of the Supreme Court of the Russian Federation.

Key words: exemption from criminal responsibility, settlement with the injured party, reparation, first offender, national legislation.

УДК 343.242 .4

ББК 67.408 .031
\end{abstract}

\section{ДИФФЕРЕНЦИРУЮЩИЕ ЭЛЕМЕНТЫ ОСВОБОЖДЕНИЯ ОТ УГОЛОВНОЙ ОТВЕТСТВЕННОСТИ В СВЯЗИ С ПРИМИРЕНИЕМ С ПОТЕРПЕВШИМ ПО УК РОССИЙСКОЙ ФЕДЕРАЦИИ, РЕСПУБЛИКИ БЕЛАРУСЬ И РЕСПУБЛИКИ КАЗАХСТАН}

\author{
Лариса Николаевна Ларионова \\ Волгоградский государственный университет, г. Волгоград, Российская Федерация
}




\section{Игорь Олегович Грунтов}

Белорусский государственный университет, г. Минск, Республика Беларусь

\section{Дмитрий Георгиевич Мороз}

Белорусский государственный университет, г. Минск, Республика Беларусь

Введение: в статье дается сравнительно-правовой анализ норм УК России, УК Республики Беларусь и УК Республики Казахстан, регламентирующих освобождение от уголовной ответственности в связи спримирением с потерпевшим, а также официальной позиции по тем же вопросам, отраженной в соответствующих постановлениях высших судебных органов указанных государств. Целями и задачами выступают выявление различий в регламентации рассматриваемого вида освобождения от ответственности по уголовным законам РФ, РБ и РК, поиск наиболее оптимальных вариантов их описания в законе и актах официального толкования. Методы: основным методом научного познания явилось сравнительно-правовое исследование, кроме того, привлекались формально-логический и системно-структурный приемы. Результаты: проанализирована система условий, с которыми законодатели России, Беларуси и Казахстана связывают возможность освобождения от уголовной ответственности в связи с примирением с потерпевшим, и на основе особенностей их описания в законодательстве, а также характеристики в постановлениях высших судебных органов выявлены общие, сходные аспекты и «национальные» особенности, присущие соответствующему правовому явлению. Предпринята попытка определения дифференцирующего влияния отдельных условий освобождения от уголовной ответственности. Обращено внимание на некоторые недостатки, присущие проанализированным нормативным актам. Область применения: предназначено для использования в законотворческой и правоприменительной деятельности, а также в научной работе. Сформулированы выводы о наличии возможностей для повышения дифференцирующего потенциала условий освобождения от уголовной ответственности в связи с примирением с потерпевшим в уголовных кодекcax Российской Федерации и Республики Беларусь, предложено внести изменения и дополнения в указанные законодательные акты и в Постановление № 19 Пленума Верховного Суда РФ.

Ключевые слова: освобождение от уголовной ответственности, примирение с потерпевшим, заглаживание вреда, лицо, впервые совершившее преступление, национальное законодательство.

\section{Введение}

Уголовные законы Российской Федерации, Республики Беларусь и Республики Казахстан изначально развивались на одной правовой основе и до сих пор имеют немало общего. И УК РФ, и УК РБ, и УК РК содержат институт освобождения от уголовной ответственности, в числе норм которого национальные законы трех государств предусматривают примирение с потерпевшим как основание принятия соответствующего процессуального решения (ст. 76 УК РФ, ст. 89 УК РБ, ст. 68 УК РК).

Положения указанных статей УК РФ и УК РБ, имея значительное формальное, текстуальное сходство, характеризуются некоторой содержательной спецификой, хотя набор условий, которыми определяется освобождение от уголовной ответственности в связи с примирением, в основном одинаков:

1) лицо, совершившее преступление, загладило причиненный вред;
2) само преступное деяние характеризуется невысоким или средним уровнем общественной опасности;

3) преступление совершено впервые.

Гораздо большей спецификой обладают положения ст. 68 УК Республики Казахстан, но и здесь имеют значение категория совершенного преступления, наличие или отсутствие криминального опыта и позитивные постпреступные действия в виде заглаживания причиненного вреда.

\section{Заглаживание причиненного вреда}

Первое из указанных условий решает восстановительную задачу и направлено на устранение или сглаживание негативных последствий криминального конфликта. Правоприменители Беларуси, России и Казахстана выработали весьма сходные толкования рассматриваемого условия.

Так, Пленум Верховного Суда Республики Беларусь уточняет: «Заглаживание нанесенного преступлением вреда может выражаться 
в материальном возмещении морального вреда, принесении потерпевшему извинения, оплате его лечения, в том числе санаторно-курортного, в компенсации упущенной выгоды, оказании иной помощи потерпевшему или совершении других действий, направленных на предотвращение, устранение или уменьшение наступивших от преступления вредных последствий» [2]. Кроме того, одним из распространенных способов заглаживания вреда является возмещение причиненного ущерба.

Аналогичное толкование предлагают Пленум Верховного Суда РФ [3] и Верховный Суд Республики Казахстан [4].

Признанная законодателем возможность разрешения криминального конфликта консенсуальным путем, посредством примирения его сторон, предполагает и то, что выбор одного или нескольких вариантов заглаживания вреда должен определяться по соглашению между участниками конфликта. Ведущая роль при этом, думается, принадлежит потерпевшему как пострадавшей стороне, прощения которого, как правило, ищет лицо, совершившее преступление. В том же духе мыслит и правоприменитель: «Способы заглаживания вреда, а также размер его возмещения определяются потерпевшим» [3]; «Если ущерб от преступления остался невозмещенным ввиду отказа потерпевшего ... от предъявления требований по его возмещению, решение вопроса об освобождении обвиняемого от уголовной ответственности возможно при условии заглаживания им нанесенного вреда иным образом» [2]; «Добровольный отказ потерпевшего ... от требований к лицу, совершившему уголовное правонарушение, о заглаживании вреда не может расцениваться как невыполнение им обязанности загладить этот вред и сам по себе не может быть препятствием для примирения сторон» [4].

\section{Характеристика преступлений, при совершении которых допустимо освобождение от уголовной ответственности в связи с примирением}

Второе условие касается круга преступлений, при совершении которых лицо может претендовать на освобождение от уголовной ответственности: преступления небольшой тяжести (не представляющие большой общественной опасности по УК РБ); преступления средней тяжести (менее тяжкие - по УК РБ). Кроме того, согласно ч. 2 ст. 68 УК Республики Казахстан это могут быть и тяжкие преступления в случае их совершения определенными субъектами: несовершеннолетними, беременными женщинами, женщинами, имеющими малолетних детей, мужчинами, воспитывающими в одиночку малолетних детей, женщинами в возрасте пятидесяти восьми и свыше лет, мужчинами в возрасте шестидесяти трех и свыше лет.

Однако законодатель Казахстана не ограничился указанием категорий, но обратил внимание и на другие характеристики преступлений, исключив из числа посягательств, при совершении которых возможно освобождение от ответственности за примирением, следующие деяния: преступления небольшой или средней тяжести, связанные с причинением смерти; тяжкие преступления, связанные с причинением смерти или тяжкого вреда здоровью; преступления против половой неприкосновенности несовершеннолетних, за исключением случаев их совершения лицом, не достигшим совершеннолетия, в отношении несовершеннолетнего в возрасте от четырнадцати до восемнадцати лет; преступления по неосторожности, повлекшие смерть человека либо смерть двух и более лиц; коррупционное, террористическое либо экстремистское преступление; преступление, совершенное в составе преступной группы.

Считая правильным такое решение казахских законотворцев, мы вместе с тем не видим смысла во включении в «исключающий перечень» преступлений, совершаемых по неосторожности, повлекших смерть человека либо смерть двух и более лиц (ч. 4 ст. 68 УК РК), поскольку они являются частью более широкого понятия, также фигурирующего в названном перечне, - преступлений, связанных с причинением смерти (ч. 1, 2 ст. 68). Помимо того, что в данном случае имеет место частичное дублирование, у правоприменителя может сложиться ложный вывод о допустимости освобождения от уголовной ответственности в связи с примирением в ситуации совершения умышленного преступле- 
ния, повлекшего смерть человека, что по общему правилу рассматривается как более опасное деяние, нежели аналогичное преступление, но совершенное по неосторожности.

Справедливости ради стоит сказать, что белорусский правоприменитель также считает недопустимым освобождение от уголовной ответственности в связи с примирением, если соответствующее заявление «исходит от лица, осуществляющего в уголовном процессе права потерпевшего по делу о преступлении, последствием которого явилась смерть потерпевшего» [2], хотя ни уголовный, ни уголовнопроцессуальный закон подобного исключения не оговаривает. К сожалению, Пленум Верховного Суда РФ пошел по другому пути [3]. Российская практика знает немало примеров освобождения от ответственности в связи с примирением с потерпевшим, когда собственно потерпевшего уже нет, он погиб в результате криминального конфликта.

Рассматривая круг преступлений, по которым допустимо освобождение от уголовной ответственности за примирением, важно выяснить, на какую группу отношений посягают соответствующие деяния. Как быть в случаях совершения посягательств против интересов государства и общества?

Прямой ответ на этот вопрос в УК РБ и УК РФ отсутствует, однако он представлен в Постановлении Пленума Верховного Суда РБ от 29 марта 2012 г. № 1: «Если лицом совершено преступление, посягающее сразу на несколько объектов уголовно-правовой охраны (например... наряду с общественным порядком, также и на здоровье или собственность гражданина), освобождение обвиняемого от уголовной ответственности по ст. 89 УК не исключается. Однако суду при решении вопроса об освобождении обвиняемого от уголовной ответственности следует в целях обеспечения защиты интересов как потерпевшего, так и государства и общества учитывать общественную опасность последствий, наступивших для каждого объекта преступного посягательства» [2]. Некий намек на такое же решение содержится и в постановлении Пленума Верховного Суда РФ: «При разрешении вопроса об освобождении от уголовной ответственности судам следует также учитывать конкретные обсто- ятельства уголовного дела, включая особенности и число объектов преступного посягательства, их приоритет...» [3].

Неоднозначным видится решение, содержащееся в ч. 3 ст. 68 УК РК. С одной стороны, констатируется возможность освобождения от уголовной ответственности и в случае, когда уголовным правонарушением причиняется вред охраняемым законом интересам государства и общества, с другой - законодатель уже не говорит о примирении с потерпевшим как основании освобождения в рамках данной статьи, а выдвигает в качестве условий наряду с заглаживанием вреда еще и чистосердечное раскаяние, по сути вводя элементы, характерные для другого вида освобождения от ответственности - в связи с деятельным раскаянием.

\section{Совершение преступления впервые}

В УК России данное условие предусмотрено как непреложное, тогда как по законам Беларуси и Казахстана оно приобретает значение обязательного лишь в случае совершения менее тяжкого (УК РБ) или тяжкого (УК РК) преступления. Один из соавторов статьи уже высказывался о необходимости исключения данного условия из ст. 76 УК РФ [1, с. 281-282], поэтому отметим здесь, что ограничение сферы актуальности этого фактора ситуациями совершения более опасных преступлений повышает дифференцирующий потенциал института освобождения от уголовной ответственности и придает рассматриваемому условию самостоятельное дифференцирующее значение в рамках анализируемого вида освобождения от уголовной ответственности.

Что же касается толкования данного условия на уровне постановлений высших судебных органов, то здесь в основном наблюдается одинаковый подход, за исключением того, что Пленум Верховного Суда РФ даже при наличии в поведении лица совокупности преступлений считает такого субъекта впервые совершившим преступление, поскольку ни за одно из них лицо ранее не было осуждено [2]. Однако мы можем признать это правильным лишь для случаев идеальной, но не реальной совокупности преступлений. 


\section{Выводы}

Дифференцирующими элементами в нормах об освобождении от уголовной ответственности в связи с примирением с потерпевшим являются предусмотренные уголовным законом условия, при наличии которых может быть принято соответствующее решение по уголовному делу.

Белорусский и российский законодатели в недостаточной степени используют дифференцирующий потенциал обозначенных условий, излишне лаконично описывая преступления, по которым допустимо освобождение за примирением, путем указания только на их категориальную принадлежность. Целесообразно дополнить ст. 76 УК РФ и ст. 89 УК РБ ч. 2 , аналогичной по содержанию ч. 4 ст. 68 УК РК. Кроме того, из ст. 76 УК РФ следует исключить условие совершение преступления впервые, по крайней мере в сочетании с преступлением небольшой тяжести.

В соответствующей корректировке нуждается и Постановление Пленума Верховного Суда РФ от 27 июня 2013 г. № 19.

\section{СПИСОК ЛИТЕРАТУРЫ}

1. Ларионова, Л. Н. О природе освобождения от уголовной ответственности в связи с примирением с потерпевшим и некоторых процессуальных аспектах применения данного института / Л. Н. Ларионова, Л. В. Лобанова // Проблемы освобождения от уголовной ответственности и наказания по законодательству Республики Беларусь, России и Украины: уголовно-правовой и уголовно-процессуальный аспекты : сб. ст. - Волгоград : Изд-во ВолГУ, 2012. - С. 276-287.

2. О практике применения судами статей 86 , 88, 89 Уголовного кодекса Республики Беларусь, предусматривающих возможность освобождения лица от уголовной ответственности : постановление Пленума Верхов. Суда Респ. Беларусь от 29 марта 2012 г. № 1 // Сайт Верховного Суда Республики Беларусь. - Электрон. текстовые дан. - Режим доступа: http://court.gov.by/jurisprudence/Post_plen/ criminal/toco/cae9d2aedc1bdaa2.html (дата обращения: 07.06.2017). - Загл. с экрана.

3. О применении судами законодательства, регламентирующего основания и порядок освобождения от уголовной ответственности : постановление Пленума Верхов. Суда Рос. Федерации от 27 июня 2013 г. № 19 // Сайт Верховного Суда РФ.-
Электрон. текстовые дан. - Режим доступа: http:// www.vsrf.ru/Show pdf.php?Id=8715 (дата обращения: 07.06.2017). - Загл. с экрана.

4. О судебной практике по применению статьи 68 Уголовного кодекса Республики Казахстан : норматив. постановление Верхов. Суда Респ. Казахстан от 21 июня 2001 г. № 4 // Информационно-правовая система нормативных правовых актов Республики Казахстан. - Электрон. текстовые дан. Режим доступа: http://adilet.zan.kz/rus/docs/ P01000004S_(дата обращения: 09.06.2017). -Загл. с экрана.

\section{REFERENCES}

1. Larionova L.N., Lobanova L.V. O prirode osvobozhdeniya ot ugolovnoy otvetstvennosti $\mathrm{v}$ svyazi s primireniem s poterpevshim i nekotorykh protsessualnykh aspektakh primeneniya dannogo instituta [On the Nature of Exemption from Criminal Responsibility in Connection with Reconciliation with the Victim, and Some Procedural Aspects of Applying this Institution]. Problemy osvobozhdeniya ot ugolovnoy otvetstvennosti $i$ nakazaniya po zakonodatelstvu Respubliki Belarus, Rossii i Ukrainy: ugolovno-pravovoy $i$ ugolovno-protsessualnyy aspekty: sb. st. [Problems of Exemption from Criminal Liability and Punishment under the Legislation of the Republic of Belarus, Russia and Ukraine: Criminal Legal and Criminal Procedural Aspects. Collected Articles]. Volgograd, Izd-vo VolGU, 2012, pp. 276-287.

2. O praktike primeneniya sudami statey $86,88,89$ Ugolovnogo kodeksa Respubliki Belarus, predusmatrivayushchikh vozmozhnost osvobozhdeniya litsa ot ugolovnoy otvetstvennosti: postanovlenie Plenuma Verkhovnogo Suda Respubliki Belarus ot 29 marta 2012 g. № 1 [On Practice of Application by Courts of Articles 86, 88, 89 of the Criminal Code of the Republic of Belarus, including the Possibility of Exemption from Criminal Responsibility. The Resolution of Plenum of the Supreme Court of the Republic of Belarus of March 29, 2012 no. 1]. Sayt Verkhovnogo Suda Respubliki Belarus [Website of the Supreme Court of the Republic of Belarus]. URL: http://court.gov.by/jurisprudence/ Post_plen/criminal/toco/cae9d2aedc1bdaa2.html. (accessed June 7, 2017).

3. O primenenii sudami zakonodatelstva, reglamentiruyushchego osnovaniya i poryadok osvobozhdeniya ot ugolovnoy otvetstvennosti: postanovlenie Plenuma Verkhovnogo Suda Ros. Federatsii ot 27 iyunya 2013 g. № 19 [On the Application by Courts of the Legislation Regulating the Grounds and Procedure of Exemption from Criminal Responsibility: Resolution of the Plenum of the Supreme Court of the Russian Federation of June 27, 2013 no. 19]. Sayt Verkhovnogo Suda RF [Website of 
the Supreme Court of the Russian Federation]. URL: http://www.vsrf.ru/Show_pdf.php?Id=8715. (accessed June 7, 2017).

4. O sudebnoy praktike po primeneniyu statyi 68 Ugolovnogo kodeksa Respubliki Kazakhstan: normativ. postanovlenie Verkhovnogo Suda Respubliki Kazakhstan ot 21 iyunya 2001 g. № 4 [On Judicial Practice of Applying Article 68 of the Criminal
Code of the Republic of Kazakhstan. Regulatory Statute of the Supreme Court of the Republic of Kazakhstan of June 21, 2001 no. 4]. Informatsionnopravovaya sistema normativnykh pravovykh aktov Respubliki Kazakhstan [Information and Legal System of Normative Legal Acts of the Republic of Kazakhstan]. URL: http://adilet.zan.kz/rus/docs/ P01000004S. (accessed June 9, 2017).

\section{Information about the Authors}

Larisa N. Larionova, Candidate of Juridical Sciences, Associate Professor, Department of Criminal Law, Volgograd State University, Prosp. Universitetsky, 100, 400062 Volgograd, Russian Federation, larionova@volsu.ru.

Igor O. Gruntov, Doctor of Juridical Sciences, Associate Professor, Head of the Department of Criminal Law, Belarusian State University, Leningradskaya St., 8, 220030 Minsk, Republic of Belarus, crimlaw.bsu@tut.by.

Dmitry G. Moroz, Candidate of Juridical Sciences, Associate Professor, Department of Criminal Law, Belarusian State University, Leningradskaya St., 8, 220030 Minsk, Republic of Belarus, crimlaw.bsu@tut.by.

\section{Информация об авторах}

Лариса Николаевна Ларионова, кандидат юридических наук, доцент кафедры уголовного права, Волгоградский государственный университет, просп. Университетский, 100, 400062 г. Волгоград, Российская Федерация, larionova@volsu.ru.

Игорь Олегович Грунтов, доктор юридических наук, доцент, заведующий кафедрой уголовного права, Белорусский государственный университет, ул. Ленинградская, 8, 220030 г. Минск, Республика Беларусь, crimlaw.bsu@tut.by.

Дмитрий Георгиевич Мороз, кандидат юридических наук, доцент кафедры уголовного права, Белорусский государственный университет, ул. Ленинградская, 8, 220030 г. Минск, Республика Беларусь, crimlaw.bsu@tut.by. 